\title{
PROPOSTA DE ORGANIZAÇÃO DE VERBETE EM GLOSSÁRIOS TERMINOLÓGICOS BILÍNGUES - LÍNGUA BRASILEIRA DE SINAIS E LÍNGUA PORTUGUESA
}

\author{
Patricia Tuxi* \\ Universidade de Brasília
}

\begin{abstract}
Resumo: Este trabalho, que se insere na linha de pesquisa da Tradução e Terminologia, apresenta como objeto de estudo os termos base utilizado nos discursos políticos e educacionais que permeiam os eventos de conferências nacionais. Em respeito à Lei 10436/2002 e o Decreto 5626/2005 é direito do Surdo ter acesso às informações em Língua Brasileira de Sinais - Libras. Uma das formas de garantir esse direito é a presença do tradutor e do intérprete que ao atuar em áreas com temas especializados devem deter o conhecimento das terminologias específicas utilizadas em contextos diversos. $\mathrm{O}$ estudo em curso tem como base a Metodologia para elaboração dicionários e glossários de Faulstich (1995). A pesquisa segue a abordagem da Socioterminologia e, como procedimento: i) reconhecimento e identificação do público-alvo; ii) delimitação da área pesquisada; iii) coleta e organização dos dados; iv) organização do glossário e teste de validade. O resultado da pesquisa é a apresentação de uma proposta de organização de verbete de um Glossário Bilíngue de Terminologia voltado para a área de conferências, que possa servir como fonte de consulta e
\end{abstract}

* Doutoranda na área da Linguística pela Universidade de Brasília e Mestre em Educação pela Universidade de Brasília - UNB (2009). Tradutora e Intérprete de Língua Brasileira de Sinais - LIBRAS. Desenvolve pesquisas nas áreas de Terminologia e Léxico da Libras. Professora Assistente no Departamento de Linguística, Português e Línguas Clássicas - LIP, do Instituto de Letras - IL, na Universidade de Brasília - UnB. Brasília, Distrito Federal, Brasil. Email: ptuxiinterprete@gmail.com 
formação dos tradutores e dos intérpretes que atuam nos eventos de conferências nacionais.

Palavras-chave: Verbete. Glossário Terminológico Bilíngue. Intérprete de Língua Brasileira de Sinais.

\title{
PROPOSED ENTRY OF ORGANIZATION IN BILINGUAL GLOSSARIES TERMINOLOGY - SIGN LANGUAGE AND BRAZILIAN PORTUGUESE LANGUAGE
}

\begin{abstract}
This work, which is inserted in the research line of Translation and Terminology, presented as an object of study the basic terms used in political and educational discourses that permeate national conference events. In respect to the Law 10436/2002 and Decree 5626/2005 is right for the Deaf have access to information in Brazilian Sign Language - Libras. One way to ensure this right is the presence of translator and interpreter to act in areas with specialized subjects should retain the knowledge of the specific terminology used in different contexts. The current study is based on the methodology for the preparation of dictionaries and glossaries Faulstich (1995). The research follows the approach of Socioterminology and as following: i) recognition and identification of the target audience; ii) delimitation of the surveyed area; iii) collection and organization of data; iv) organization glossary and validity test. The search result is the presentation of a proposal for entry of organizing a Terminology Glossary Bilingual facing the conference area that can serve as a reference source and training of translators and interpreters who work in the national conference events.
\end{abstract}

Keywords: Entry . Bilingual Terminology Glossary . Brazilian Sign Language Interpreter signs.

\section{Introdução}

É significativo o aumento das representações surdas e por consequência o uso da Língua Brasileira de Sinais - Libras no cenário político, educacional e social nas últimas décadas. Com o reconhecimento da Libras, pela Lei 10.436/2002, como língua nacional usada pelas comunidades surdas do Brasil o sujeito Surdo passou a ter acesso às diversas áreas sociais, sendo garantido por 
lei o direito à acessibilidade linguística. Dentre estes espaços há o contexto das conferências, onde todas as informações devem ser disponibilizadas na primeira língua do Surdo, ou seja, a Libras. Neste panorama encontra-se um dos meios que irá garantir essa acessibilidade: o tradutor e o intérprete da Língua Brasileira de Sinais. Este profissional atua entre a língua portuguesa e a Libras tendo como função traduzir ou interpretar os conceitos abstratos e linguísticos de cada uma das línguas respeitando o sentido e a forma das ideias e signos envolvidos.

Sua atuação demanda proficiência linguística e há necessidade de formação contínua calcada em uma bibliografia específica para a área. Apesar de pesquisas no campo da Libras envolvendo o processo de tradução e interpretação crescerem de forma significativa, a área de conferencias ainda possui poucos resultados. Em um levantamento realizado em sites acadêmicos como: scielo, google acadêmico, ERIC e também em bibliografias específicas da área da Língua Brasileira de Sinais como a coletânea dos Estudos Surdos ou Estudos da Língua Brasileira de Sinais é possível constatar a baixa produção, de pesquisas voltadas para o intérprete de conferência. Porém apesar de não registar de forma significativa textos da parte acadêmica, no decorrer da recolha dos dados foram encontrados vocabulários de sinais, que são apresentados como ferramentas de auxílio para intérpretes de Libras no preparo e estudo de suas atuações.

Na língua portuguesa há produções significativas de materiais que apoiam as práticas dos processos de interpretação e tradução como os glossários e dicionários. Sites como o CITRA - Centro Interdepartamental de Tradução e Terminologia (CITRAT) que faz parte do Departamento da Faculdade de Letras da Universidade de São Paulo - USP disponibilizam glossários de termos de especialidade que para Krieger e Maciel (2011) são elementos fundamentais na formação do tradutor e intérprete. As autoras afirmam a necessidade contínua de pesquisas com produção de material, pois auxiliam na formação, esclarecem aspectos relacionados à ambiguidade e em ambientes onde vários intérpretes atuam simultaneamente, 
condicionam uma padronização de sinais o que se mostra essencial para os usuários e participantes de grandes eventos. Ao observar o aumento da participação de surdos em conferências e conselhos nacionais é evidente que a necessidade de produção de material e estudos que auxiliem no processo de padronização de sinais terminológicos não se destina apenas as línguas orais, mas também a língua de sinais.

Pesquisas que apontam para a necessidade de produção de materiais voltados para a organização dos termos criados na língua de sinais já são desenvolvidas. Segundo Castro Júnior (2011), nos espaços educacionais onde os Surdos estão inseridos ocorre à criação de diferentes tipos de sinais, relacionados a um mesmo conceito e termo. Deve ser destacado que esta pesquisa acha importante o surgimento de novos termos, mas é preciso que haja um aporte terminológico de uso e organização. O autor observou a diversidade de sinais para um único termo dentro de uma mesma escola. Os sinais eram na verdade pensados em uma sala de aula específica, mas não eram validados junto aos demais alunos surdos ou grupos sociais ali presentes. Como consequência várias criações de um mesmo conceito em um único local de uso, ou seja, vários professores, ou intérpretes usando sinais diferentes para um mesmo termo de especificidade.

Nos estudos desenvolvidos na dissertação de mestrado Tuxi (2009) descreve a situação que ocorrem em uma determinada escola onde um termo apresenta quatro formas de serem sinalizados. Esse "fenômeno" não é uma variação linguística ou mudança de significados, mas sim o uso diferenciado de sinais utilizados pelos intérpretes que nos momentos de aula "convencionam" informalmente os sinais a partir do conceito apresentado pelo professor. De acordo com Oliveira (2010) um dos motivos dessa variação de sinais é que os termos técnicos existentes na língua portuguesa ainda estão em processo de neologismo na língua de sinais. Com o acesso do Surdo às diversas esferas sociais, o processo de tradução tem gerado uma extensa lista de verbetes com termos técnicos específicos em vários espaços sociais. A autora destaca também que o 
acervo lexical de todas as línguas se renova e com a língua de sinais não seria diferente. Todos esses novos léxicos, especializados ou comuns, necessitam de uma organização lexicográfica ou terminográfica, por meio de glossários ou dicionários em língua de sinais.

Pesquisas voltadas para elaboração de glossários, vocabulários de especialidade e enciclopédias baseadas na língua de sinais, já vêm sendo desenvolvidas. Na área da educação é possível apontar o trabalho de Castro Júnior (2014) que criou um banco de dados voltados para os termos de especialidade do ensino médio nas áreas de Geografia, Biologia, Matemática, Física, Química entre outras disciplinas que compõem o currículo do segundo grau. Costa (2012) no seu trabalho de mestrado apresenta uma Proposta de modelo de Enciclopédia Visual Bilíngue Juvenil denominado Enciclolibras do corpo humano. Ribeiro (2013) Glossário Bilíngue da Língua de Sinais Brasileira: Criação de sinais dos termos da música. Todos os citados fazem parte do trabalho desenvolvido no Laboratório de Linguística de Língua de Sinais - LabLibras do CentroLexTerm da Universidade de Brasília - UnB.

Outro trabalho de destaque nesta área, é o desenvolvido na Universidade Federal de Santa Catariana - UFSC por meio do Glossário Letras - Libras, um repertório lexicográfico de termos especializados no ambiente virtual voltado para o curso acima citado. Tem como objeto maior oferecer um recurso didático que auxilie no processo de ensino aprendizagem.

$\mathrm{Na}$ área de léxico de especialidade, fora do ambiente educacional, é possível encontrar materiais em língua de sinais em diversos sites, boa parte em formato de blogs, que tem o objetivo de disponibilizar um banco de sinais terminológicos que possam vir a auxiliar o tradutor e o intérprete. Dentre os trabalhos realizados é possível destacar:

- Projeto Sinal Aberto - (https://projetosinalaberto.wordpress. $\mathrm{com} /$ ) Projeto voltado para o tradutor e intérprete de Libras - Língua Portuguesa. Tem como objetivo formar um banco de traduções, com conteúdos novos para auxiliar no trabalho 
de tradução e interpretação. Apresenta uma lista de palavras, juntamente com a fonte, isto é, o texto (sinalizado) onde os sinais aparecem. Apresenta também o contexto de onde cada sinal foi retirado, para ajudar a entender o significado ligado a cada um dos usos. No site são destacados como pesquisadores responsáveis pelo projeto: Dafny Hespanhol e Rodrigo Leal.

- Terminologia da Política Brasileira - LIBRAS / Língua Portuguesa - (http://politicaemlibras.blogspot.com.br/) Grupo de Estudos Lexicais, formado por Tradutores e Intérpretes de Língua Brasileira de Sinais - Libras que atuam nos quadros funcionais dos poderes: Executivo e Legislativo Federal. No site são destacados como pesquisadores responsáveis pelo projeto: Aline Mendes, Daniel Madureira e José Ednilson Júnior.

- Glossário Bilíngue de Amamentação em Libras (Língua Brasileira de Sinais) - (http://www.saude.ms.gov.br/controle/ ShowFile.php?id=115652) Glossário elaborado pela equipe de profissionais do Centro de Capacitação de Profissionais da educação e de Atendimento às Pessoas com Surdez (CAS) de Mato Grosso do Sul.

- Glossário de sinais-termos dos Orixás da nação Ketu - (https://youtu.be/LC2bq0rIxnc) Léxico Alfabético Bilíngue Libras/Português que faz parte do projeto de pesquisa em fase de conclusão do Programa de Pós-Graduação em Língua e Cultura da Universidade Federal da Bahia (UFBA), inserida na linha de pesquisa Tradução Audiovisual e Acessibilidade. No site são destacados como pesquisadores responsáveis pelo projeto: Neemias Santana e Wermerson Silva.

Todos os trabalhos apresentados acima são vocabulários, glossários ou listas lexicais de especificidades terminológicas que podem ser consideras importantes para a formação e atuação do 
tradutor e do intérprete de Libras. Porém é possível perceber a divergência de formatação de como os termos são apresentados. Em alguns o termo é traduzido da Língua Portuguesa para a Língua Brasileira de Sinais e tem um desenho ou imagem como aporte visual do elemento descrito. Nas listas de vocábulos bilíngues as entradas são em ordem alfabética da Língua Portuguesa, seguidas do sinal equivalente em Libras com as definições apresentadas em português. Em alguns casos foram observado glossários que apresentam apenas o sinal equivalente, sem nenhuma definição conceitual dos termos. No processo de pesquisa apenas um glossário, apresentou a ferramenta de contexto para uso e identificação do termo no uso pragmático.

$O$ presente trabalho entende a importância dos demais e vem se juntar com o objetivo de apresentar uma proposta de organização de verbete para glossários bilíngues Libras - Língua Portuguesa. A pesquisa deseja demonstrar a importância da criação de uma possível proposta que auxilie no processo de regularização do verbete terminológico. Os verbetes possuem uma estrutura a partir da categoria a qual pertence. Segundo Borba (2003) as macroestruturas e microestruturas de obras lexicográficas ou terminográficas devem apresentar uma seleção de elementos descritivos próprios a cada público de uso e objetivo proposto.

Segundo Faria- Nascimento (2009) se faz necessário registar e organizar os novos termos criados de uma área em um banco de dados que sirva de apoio e consulta para tradutores e também intérpretes da Língua Brasileira de Sinais e demais usuários da língua. A pesquisa aqui desenvolvida entende que o desafio de tal organização está em como esse glossário deverá ser elaborado e ordenado. É necessário inicialmente, estabelecer as diferenças entre o que é vocabulário, ou dicionário e como se constitui uma lista de léxico especializado, árdua tarefa que precisa ter sempre em mente o usuário do material e sua função. Este trabalho tem a Terminologia como objeto de uso da Tradução e Interpretação da Língua Portuguesa para Libras e vice-versa. A área de estudo é a análise da palavra especializada, que na língua de sinais será aqui utilizada 
como sinal-termo. A expressão sinal-termo surgiu em 2012, criada por Faulstich, e aparece pela primeira vez na dissertação de mestrado de Messias Ramos Costa, denominada Proposta de modelo de enciclopédia bilíngue juvenil: Enciclolibras (2012). Durante as discussões de natureza lexicográfica, Faulstich percebeu que a expressão sinal ou sinais não correspondia ao significado de termos usados no contexto das linguagens de especialidade, especialmente na terminologia científica ou técnica. A designação sinais serve para os significados usados no vocabulário comum da Libras . Os vocabulários terminológicos exigem expressão precisa para designar significados. Para a informação conveniente, a expressão sinal-termo é a que corresponde às necessidades de uso especializado.

\section{A relação da terminologia com a tradução e a interpretação}

Ao analisar a tradução, entre duas línguas, tendo como objeto um discurso especializado, fica claro a necessidade de se estabelecer a relação entre a tradução e a terminologia. Apesar de serem disciplinas autônomas com objetos de estudo e pressupostos teóricos distintos, como afirma Ramos (2001), ambas as áreas se cruzam, pois seus objetos são oriundos das ciências comuns às duas áreas como as ciências cognitivas, ciências da linguagem e ciências da comunicação. Para compor um trabalho que aborda a tradução e terminologia, se faz necessário entender um pouco mais sobre os conceitos que compõem cada uma das áreas.

Segundo Faulstich (2003) a terminologia é o campo da ciência que estuda o léxico de especialidade, por meio dos mecanismos que evidenciam os princípios linguísticos. A autora afirma que os estudos da terminologia focalizam mais o conteúdo semântico do que a forma de um termo e a função que este desempenha no discurso especializado. Para Pavel e Nolet (2002) o princípio da terminologia é o estudo científico dos conceitos e termos usados nas línguas de especialidade. Em seus estudos Sager (1990) concebe a Terminologia como um conjunto de práticas que envolvem 
a criação, a coleta, a explicação e a apresentação de repertórios em vários meios eletrônicos e impressos. Cabré (1993) entende a terminologia como a representante do componente lexical das chamadas linguagens de especialidade e sua utilização favorece a comunicação entre especialistas. Krieger (2011) afirma que a terminologia é a atividade que consiste principalmente em realizar a coleta de termos, analise dos mesmos, registrar em meio eletrônico ou modelo de impressão no objetivo final de gerar uma base de dados terminológicos.

De acordo com a pesquisa realizada por Marini Satia (2013) a Terminologia moderna surge nos fins do século XIX e início do século XX com os estudos de Eugen Wuster (1898-1977) que desenvolveu a Teoria Geral da Terminologia (TGT). Dois significativos trabalhos, desenvolvidos pelo autor, o levam a ser considerado na comunidade linguística com foco no léxico, como o "pai" da terminologia. Os trabalhos foram: Die internationale Sprachnormung in der Technik, besonders in der Elektronik (1931) e o Dictionnaire multilingue de la machine-outil: notions fondamentales ( 1968). A primeira obra apresentava a metodologia e normas aplicadas à terminologia, com vistas a evitar o surgimento de ambiguidades nas comunicações científicas e técnicas. Já a segunda é uma obra na qual ele dá um passo em direção ao estudo onomasiológico. (CRUZ, 2012)

Para Cabré (2003) um dos objetivos maiores da TGT é eliminar a ambiguidade de linguagens técnicas por meio de uma possível padronização da terminologia e assim auxiliar os profissionais a utilizarem as linguagens técnicas que até o momento apresentavam formas distintas de uso e representações. Para a autora, Wuster desejava estabelecer a terminologia como uma disciplina e dar-lhe um status de ciência. Porém em virtude do não contemplar das áreas especializadas e da ideia de algo fechado e pronto sem possíveis variações linguísticas, surge a Teoria Comunicativa da Terminologia (TCT) desenvolvida por Maria Teresa Cabré. A TCT passa a ser vista com uma teoria que abrange mais conceitos e suas diversas características. 
A TCT advoga pela poliedricidade do termo, defende seu caráter comunicativo, aceita a variação ou sinonímia (na qual dois ou mais termos podem se referir a um mesmo conceito), diz que o termo faz parte da linguagem natural, e que a terminologia é temática, pois se refere a um tema específico. (MARINI, 2013, p.40).

Neste processo, a terminologia é vista com parte de um sistema linguístico constituído de palavras que quando empregados dentro de uma linguagem de especialidade passam a coexistir com signos linguísticos com funções distintas.

Outra abordagem utilizada na terminologia é a socioterminologia. Para Marini (2013) a Socioterminologia é a possibilidade de se entender as várias maneiras de denominação de um mesmo conceito. Essa visão tem como base o semantismo discursivo no qual o termo está inserido fato que permite a variação de acordo com o espaço e uso que o termo se insere. Para Faulstich (2006) a socioterminologia é um refinamento do termo.

\begin{abstract}
A socioterminologia é, portanto, um ramo da terminologia que se propõe a refinar o conhecimento dos discursos especializados, científicos e técnicos, a auxiliar na planificação linguística e a oferecer recursos sobre as circunstâncias da elaboração desses discursos ao explorar as ligações entre a terminologia e a sociedade. Uma teoria socioterminológica se assenta em princípios e fundamentos que constituem os eixos principais de uma revisão prática e subsidiam as reformulações do que se fazia em anos anteriores. (FAULSTICH, 2006, p. 4).
\end{abstract}

A pesquisa, aqui desenvolvida, entende a Terminologia como área de estudo que analisa e descreve o léxico, que utilizado em um contexto específico, ou seja, diverso da língua comum, passa a ter um valor conceitual diferenciado. Essa mudança, de léxico para termo, ocorre a partir da posição que ocupa em um determinado contexto semântico de uso. A partir deste local é que a palavra dei- 
xa de ser um léxico comum e passa a ser um léxico especializado. É essa troca de valor, significado e forma da palavra que o tradutor e intérprete precisa perceber para realizar sua atuação de forma plena respeitando os significados distintos que hora permeiam o discurso comum e em outros momentos compõem a fala especializada. Por isso se faz necessário pensar a tradução ou interpretação de termos especializados.

De acordo com Segalla (2010), a palavra tradução não significa apenas um ato mecânico de traduzir de uma língua alvo para a língua fonte, mas sim um conceito amplo e profundo que envolve aspectos linguísticos, cognitivos, comunicativos, culturais e extralinguísticos além da estrutura comum da palavra. Há uma percepção semiótica do contexto a ser traduzido e principalmente para quem será traduzido. Na obra Terminologia da Tradução (2013) o termo tradução aparece com o seguinte conceito para a entrada:

Operação de transferência interlinguística que consiste em interpretar o $<$ sentido $>$ de um $<$ texto de partida $>$ e em produzir um texto de chegada, procurando estabelecer uma relação de equivalência entre os dois, segundo os parâmetros inerentes à comunicação e dentro dos limites das restrições impostas pelo tradutor. (CORMIER et al, 2013, p. 112).

Para Guerini e Pereira (2008) em Introdução aos Estudos da Tradução, a tradução não é somente a transferência de textos de uma língua para outra, mas também um desenvolvimento de processos correlatos, que vão além da visão de equivalência linguística, do texto fonte para o texto alvo onde haja uma atitude diferenciada com base nos processos culturais envolvidos. Neste prisma é possível perceber a existência vasta de tipos de transações mediadas pela figura do tradutor e do intérprete.

Roman Jakobson em seu artigo " “Os aspectos linguísticos da tradução“" (1995), apresentado na releitura de Scherer e Kader (2012), estabelece uma divisão dos tipos de tradução, são eles: 
1. Tradução intralingual (que consiste na interpretação dos signos verbais por meio de outros signos da mesma língua);

2. Tradução interlingual (que consiste na interpretação dos signos verbais por meio de alguma outra língua) e

3. Tradução interssemiótica (que consiste na interpretação dos signos verbais por meio de sistemas de signos não verbais).

Neste trabalho a ideia de tradução adotada tem como base o conceito de Umberto Eco.

uma tradução não diz respeito apenas a uma passagem entre duas línguas, mas entre duas culturas, ou duas enciclopédias. Um tradutor não deve levar em conta somente as regras estritamente linguísticas, mas também os elementos culturais, no sentido mais amplo do termo. (2007, pg. 190).

Segundo Krieger (2011) a tradução é um ato que finda nela mesma, pois ao elaborar um texto de uma língua para outra, o objetivo final está feito. Contudo, em alguns casos para que o objetivo seja alcançado há no corpo, do discurso ou texto, termos de especialidades. Para Ramos (2001) o tradutor deve possuir conhecimento do léxico da área que atua e estabelecer uma relação com a terminologia através dos meios pela qual ela pode ser assimilada, ou seja, dicionários técnicos, glossários ou um vasto banco de dados com ferramenta de busca. Essa prática, de uso de materiais didáticos, se torna hoje viável não apenas para os tradutores, mas também para os intérpretes e principalmente os conferencistas.

O VI Congresso Internacional de Tradução e Interpretação da Associação Brasileira de Tradutores - ABRATES, que ocorreu no mês de junho de dois mil e quinze, foi um evento que demonstrou a importância das novas tecnologias para o tradutor e o intérprete conferencista. Vários painéis mostraram aplicativos que o intérprete pode e deve fazer suas anotações e criar bases de mapas mentais semânticos, ampliando assim além do seu vocabulário profissional, 
seu material de estudo que pode ser utilizado antes dos eventos, durante os eventos - nos momentos de intervalos ou substituições e no pós - evento como um banco de dados que vai sendo alimentado por novos dados e situações vivenciadas a cada conferência e que se compartilhados ainda promove uma sistematização e organização dos termos a serem utilizados em um mesmo evento

Esta pesquisa, na busca de criar um material didático que possa auxiliar no processo de interpretação da língua portuguesa para a Libras, pretende estabelecer um vínculo forte entre a terminologia e o tradução e interpretação por meio da proposta de organização de verbete em glossários terminológicos bilíngues - língua brasileira de sinais e língua portuguesa, buscando elucidar como essa relação se estabelece e de que forma o glossário, no caso o verbete que o compõem pode auxiliar na efetivação de compreensão dos sentidos linguísticos que ambas as línguas possuem.

\section{O glossário como uma ferramenta terminológica}

Ao se falar na criação de um glossário é preciso entender a área que é responsável por este trabalho. O glossário é um produto terminológico, assim como o vocabulário, dicionários e normas terminológicas.

Para Correia (2009)

um glossário é uma lista restrita de vocábulos de um determinado domínio do conhecimento, de um determinado registro linguístico (por exemplo, o calão a gíria), específicos da obra de um ator, constituída por neologismos, arcaísmos, regionalismos, etc. o glossário distingue-se do dicionário não apenas pelo número reduzido de entradas, mas também pela possibilidade de reduzir as informações apresentadas. (CORREIA, 2009, p. 31). 
Historicamente o glossário teve sua origem como uma breve lista de palavras ou termos, com seus significados. Situados normalmente no final de textos como formas de serem consultados (KRIEGER, 2006).

Para Faulstich (2014), glossário é:

\begin{abstract}
[...] repertório de termos, normalmente de uma área, apresentados somente em ordem sistêmica ou somente em ordem alfabética. O ideal é que um glossário seja elaborado e concluído abrangendo tanto a ordem sistêmica quanto a ordem alfabética, assim o leitor não perde a informação que está contida numa remissão de termos. em um glossário um verbete apresenta as informações registradas na ficha de terminologia de cada termo, de acordo com a constituição que o elaborador estruturou a ficha. é preciso estar atendo para essa constituição, a fim de evitar transformar um glossário em um léxico. (FAULSTICH, 2014, p.1).
\end{abstract}

No curso de Letras-Libras glossário é entendido como uma ferramenta que auxilia no processo de elucidação de termos-técnicos que possuem significados e sentidos ainda pouco conhecidos para o público a quem se destina o curso principalmente, no caso os surdos. (OLIVEIRA e STUMPF, 2013).

De acordo com Faulstich (1995) os glossários podem ser divididos em três categorias a partir das características do seu repertório:

i. repertório que define termos de uma área científica ou técnica, dispostos em ordem alfabética, podendo apresentar ou não remissivas;

ii. repertório em que os termos, normalmente de uma área, são apresentados em ordem sistemática, acompanhados de informação gramatical, definição, remissivas podendo apresentar ou não contexto de ocorrência. A autora destaca em nota que os glossários em ordem alfabética e os em ordem sistemática podem também conter sinonímia variantes e equivalentes. 
iii. repertório em que os termos são apresentados em ordem alfabética ou em ordem sistemática seguidos de informação gramatical e do contexto de ocorrência. A nota neste repertório aponta que este glossário é útil para os tradutores e os intérpretes, pois são elaborados a partir das bases textuais.

Neste trabalho adotamos o último tópico acima apresentado (iii), pois como a autora afirma é ideal para a atuação do tradutor e do intérprete. Glossários temáticos bi/trilíngues são utilizados de forma diferente pelos dois grupos: por tradutores de duas formas para buscar o termo na língua para a qual estão traduzindo e, por meio da definição, para verificar o sentido do termo e conferir se a tradução é a mais adequada para o profissional. Já no caso do intérprete possibilita a consulta aos termos que possivelmente irão surgir nas palestras que atuam, e como forma de padronização de termos especializados em caso de grandes eventos.

Neste trabalho o foco é um glossário bilíngue onde os termos de especialidade são constituídos a partir de campos semânticos pertencentes a uma determinada área social onde há necessidade de se estabelecer algumas convenções linguísticas que garantirão ao sujeito surdo o seu direito linguístico.

\section{Glossário terminológico bilíngue}

Glossários bilíngues comumente apresentam os termos dispostos em sequência nas duas línguas. Sendo que o termo, apresentados no verbete na língua fonte e seus equivalentes na língua alvo.

É necessário, no entanto alertar sobre o que se entende sobre equivalência. De acordo com Haesch (1982) a equivalência deve ser entendida como uma aproximação de sentidos e significados, sendo necessária muitas vezes recorrer a estratégias linguísticas como a perífrase ou fraseologias. $\mathrm{O}$ autor a destaca a urgência de reavaliar materiais que utilizam inversão em suas entradas. 
[...] dicionário ou léxico especializado bilíngue ideal não deveria servir nas duas direções, pois pode ocorrer que em uma das línguas não haja o equivalente exato e o terminológo tenha que dispor do recurso da perífrase. Ao inverter a nomenclatura, a perífrase não poderia encabeçar a entrada. (HAENSCH, 1982, p.399).

Para Kreiger e Finatto (2004) uma das tipologias de dicionários ou glossário é o semibilíngue, que traz em sua macroestrutura termos de áreas especializadas, que são imprescindíveis para os tradutores e esta pesquisa entende que também para os intérpretes. As autoras afirmam que diante da funcionalidade operada pelos termos especializados na transmissão de informações e tecnológicas forma uma base de conhecimento gerando uma tradução ou interpretação, que respeita a língua fonte.

Este trabalho tem o glossário terminológico bilíngue como fonte de consulta de léxicos especializados, ou seja, termos, que possam ser consultados por intérpretes da Língua Brasileira de Sinais - Libras, que atuam em conferências. Deseja apresentar um verbete, que venha a compor um glossário terminológico bilíngue, de forma que a proposta da sua estrutura auxilie á tornar mais claro e rápido o entendimento do conceito na língua portuguesa e seu referente por meio do sinal-termo, na Libras. Todo o trabalho respeita os contextos de uso de ambas as línguas. Dessa forma, fomenta-se pesquisas científicas na área da interpretação e tradução da Língua Brasileira de Sinais, além de fornecer conteúdo significativo para a melhor adequação dos profissionais tradutores e intérpretes.

\section{A macroestrutura e microestrutura do glossário terminológico}

O glossário é composto comumente por duas grandes partes, a macroestrutura e a microestrutura. Segundo Welker (2004, p. 81) a macroestrutura é a indicação de como as entradas são organizadas. 
Podem ser na forma temática ou alfabética, se todos têm o mesmo formato, se há ilustrações ou tabelas entre os verbetes. Para Barros (2004, p. 151) a macroestrutura significa a organização interna da obra composta de todas as informações pertinentes aos verbetes e sua organização. Faulstich (2010) destaca a macroestrutura, também conhecida como paralexicografica, e que esta envolve toda a obra desde a introdução, os anexos, a bibliografia e caso se faça necessário referências às origens de ilustrações, fotos ou mapas.

A microestrutura para Marini (2013) é onde ocorre a organização dos dados. Para a autora os dados devem ter como ordem: entradas; gênero; número; sinônimos; seta $(\rightarrow)$ - que traz o significado de que o termo é uma sigla e indica como o termo deve ser lido; indicação "Ver sin." remete o leitor para o sinônimo quando o termo do verbete consultado é uma variante do termo preferencial, ao qual ele é remetido; definição; nota; terminologia em língua equivalente. Nas pesquisas desenvolvidas por Faulstich (1995) o primeiro relato sobre definição e como se dá a microestrutura, traz uma estrutura definida por ela, como completa, e possui os seguintes elementos:

Verbete $=+$ entrada + categoria gramatical $(+-$ substantivo, +- sintagma terminológico, +- verbo) +- gênero +- sinônimo +- variantes +fontes + - áreas + - subáreas + -definição + - fonte + contexto + fonte + - remissivas + - equivalentes + - fontes.

Esse verbete para Faulstich (1995) representa, as possibilidades de organização e Suas classificações como: verbete pleno, verbete reduzido, verbete sintético e verbete completo. Neste trabalho, o verbete utilizado é o pleno, baseado no modelo de Faulstich (2010) desenvolvido junto a uma pesquisa de elaboração de um glossário da área de Biotecnologia no CentroLexTerm na Universidade de Brasília - UnB. 
Figura I - Verbete glossário da área de Biotecnologia

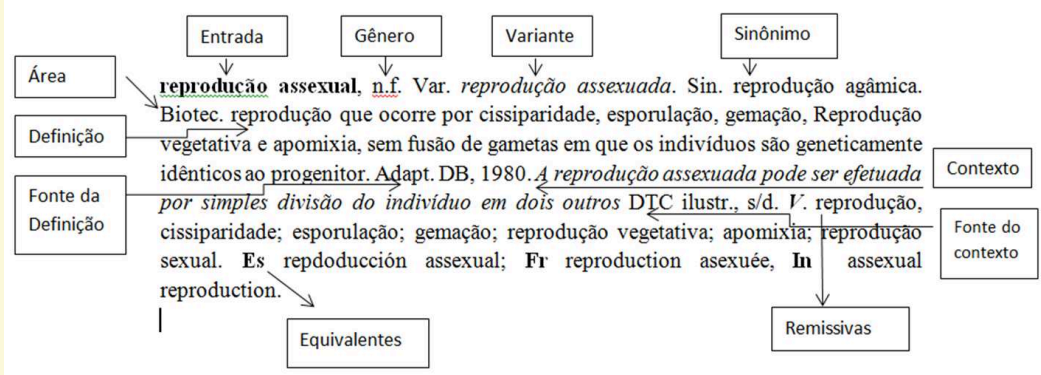

Conforme apresentado acima, os campos que compõem os verbetes são assim entendidos (FAULSTICH, 2010, p. 180-183):

- entrada: o termo propriamente dito;

- categoria gramatical: indicativo da categoria a que pertence a entrada, como, por exemplo, $\mathrm{n}=$ nome; $\mathrm{v}=$ verbo;

- gênero: indicativo do gênero a que pertence o termo na língua descrita, como $\mathrm{f}=$ feminino; $\mathrm{m}=$ masculino;

- definição: sistema de distinções recíprocas que servem para descrever conceitos pertinentes aos termos;

- fonte da definição: registro de onde foi extraída a definição;

- nota: comentário prático, linguístico ou enciclopédico, que serve para complementar as informações da definição;

- fonte da nota: registro de onde foi retirada a informação;

- sinônimo: formas coocorrentes no discurso da linguagem de especialidade cujo significado é idêntico ao do termo da entrada;

- remissiva: sistema de relação de complementaridade entre termos; inclui termos do espanhol [esp], francês [fra] e inglês [eng], que detêm o mesmo conceito.

A autora afirma que para o glossário a definição é a parte fundamental de todo o trabalho realizado na Terminografia ou Lexico- 
grafia, pois apresenta as características do que é e para que serve (FAULSTICH, 2014).

Nesse trabalho, em concordância com o da autora citada, a definição é parte estrutural mais importante do glossário, pois identifica, por meio de estratégias e usos da metalinguística, o dado de constituição do signo ali pesquisado. Acredita também que para o glossário voltado para o ato da tradução e intepretação da Libras, seja necessário também, repensar em uma estrutura linguística similar ao utilizado na definição, ou seja, o que é e para que serve, no contexto. Pois é nesse elemento da microestrutura que muitas dúvidas de uso e forma poderão ser respondidas diante dos questionamentos dos tradutores e intérpretes

A seguir será apresentada a forma de constituição utilizada nesta pesquisa, como proposta de organização de um verbete do glossário bilíngue com foco nos tradutores e intérpretes da Língua Brasileira de Sinais.

\section{Metodologia de construção do glossário}

O verbete pode ser considerado como a essência de existência de um glossário. Para que o mesmo seja apresentado como pleno, muitas etapas devem ser vencidas. Para alcançar o objetivo, de um verbete bilíngue pleno, é necessário entender do que é constituído um verbete canônico e quais as partes são essenciais para o trabalho de compreensão do sinal-termo.

Como primeiro passo foi elaborado um glossário com termos voltados para a área de conferências. Todo o processo foi realizado com base na Socioterminologia tomando como foco Faulstich (1995a; 1995b).

Para a elaboração inicial do glossário foram adotados os seguintes procedimentos:

- reconhecimento e identificação do Público-alvo;

- delimitação das áreas pesquisadas; 
- coleta e organização dos dados;

- organização do glossário;

- teste de fiabilidade.

Faz-se necessário destacar que estes procedimentos são os de base adotados pela equipe de Terminologia e Terminografia que atuam no Laboratório de Linguística de Língua Brasileira de Sinais - LabLibras na Universidade de Brasília - UnB. Em virtude das peculiaridades da língua de estuda, em alguns casos se faz necessário incluir novos procedimentos, além dos dotados por Faulstich (1995). No caso de não haver um sinal já destinado pelo termo, os pesquisadores linguistas que tem a Libras, como primeira língua, realizam reuniões com produções de sinais com base nas análises conceituais. Sendo assim ocorre em primeira instância uma validação do termo para posterior teste de fiabilidade.

\section{Reconhecimento e identificação do Público-alvo;}

Este trabalho tomou como base os sinais-termos que constituem um glossário com termos de conferências. O público-alvo inicialmente são intérpretes de língua de sinais que atuam em conferências como Rio +20 , O Conselho Nacional dos Direitos da Pessoa com Deficiência - CONADE e Conferência Nacional de Educação - CONAE. A seleção dos participantes se deu por meio de vídeos, fotos e também consultas feitas ao líderes surdos que participaram dos eventos.

\section{Delimitação das áreas pesquisadas}

Com a escolha dos eventos, em seguida foram selecionados os cadernos de resumo, livros de apresentação e folders utilizados nos congressos. Deles foram retirados textos que tivessem como foco a língua de sinais, o bilinguismo e a comunidade surda. Com os textos selecionados foi feita uma consulta a dois líderes surdos da comunidade de Brasília, sobre quais os tópicos seriam mais relevantes. 
Cada tópico escolhido foi debatido no LabLibras, em encontros semanais. O primeiro momento foi uma conversa sobre o tema, sem apresentação dos textos já selecionados. Foi feito uma análise informal, ou seja, se os textos abordavam o que para os surdos eram considerados os dados mais importantes. Com os textos selecionados passou-se a buscar termos que especificassem, delimitassem e conceituassem os tópicos mais importantes dos eventos. Em seguida esses termos foram copilados para futuramente serem apresentados dentro do contexto, dos cadernos de resumo, livros de apresentação e folders, para os intérpretes de Libras e equipe de atuação do laboratório.

\section{Coleta e organização dos dados}

O método utilizado na captação dos dados visa identificar e registrar os termos usados em duas perspectivas a da língua portuguesa e da Libras.

Para alcançar o objetivo acima proposto a coleta dos dados foi realizada pelo próprio pesquisador, que também atua como tradutora e também intérprete, com proficiência reconhecida pelo MEC por meio do PROLIBRAS - 2006 Proficiência em Tradução/Interpretação Libras/Português/Libras e com cinco linguistas pós-graduandos surdos que atuam nas pesquisas de terminologia em língua de sinais no Laboratório de Linguística de Língua de Sinais - LabLibras vinculado ao CentroLexTerm da Universidade de Brasília - UnB.

Inicialmente com os textos escolhidos foi preciso delinear os termos considerados mais importantes para a área pesquisada. $\mathrm{O}$ objetivo é apreender ao máximo os termos que constituam a essência dos eventos já anteriormente delimitados. Após a coleta foram feitos os registros dos termos em fichas terminológicas que são a base de formação dos verbetes.

A importância desse registro nas fichas terminológicas é apontada por Faulstich (1995b) que compara a ficha terminológica a uma "certidão de nascimento de um termo". 
Por esta ficha,é possível localizar o contexto do termo e recuperar as informações de onde ele foi retirado. A ficha apresenta vários campos de informações sendo possível apresentar seus vários contextos de uso. Para Martins (2007) a ficha terminológica é considerada um dos itens mais importantes do trabalho terminológico, pois esta é indispensável para a geração de glossários ou dicionários por se tratar de um registro completo e organizado de informações referentes a um termo.

De acordo com Pavel e Nolet (2002) na obra Handbook of Terminology, livro que foi adaptado para a língua portuguesa por Enilde Faulstich toda as informações coletadas são analisadas, filtradas e registradas de forma reduzida nas fichas terminológicas. Os principais elementos das fichas terminológicas são:

- área temática;

- termos;

- marcas de uso e

- provas textuais.

\section{Organização do glossário}

Após a coleta dos dados e dos registros das fichas o pesquisador inicia a informatização dos dados. Neste momento se dá a ruptura de pesquisas e padrões já existentes para a língua portuguesa e para a língua de sinais.

Para a língua portuguesa foi elaborado o verbete pleno, seguindo o modelo de Faulstich (1995), neste texto já descrito na pagina doze. Esta forma de verbete é o comumente utilizado em dicionários e glossários terminológicos. Sua forma plena é apresentada na seguinte forma:

Verbete $=+$ entrada + categoria gramatical $(+-$ substantivo, +- sintagma terminológico, +- verbo) +- gênero +- sinônimo +-variantes +fontes + - áreas + - subáreas + -definição + - fonte + contexto + fonte + - remissivas + - equivalentes + - fontes. 
Para o verbete em Libras o processo todo ainda está em fase de validação e construção, o que significa sofrer alterações a partir do uso do material. Inicialmente os sinais-termos, selecionados do texto de origem já citado, foram apresentados na forma de imagem - caso o conceito assim permitisse- ou contextos de diálogos onde o termo era empregado por meio de classificadores. A equipe, composta de cinco linguistas surdos, analisa o contexto e caso não exista sinais, já utilizados pela comunidade, cria um sinal para o conceito gravado e a estrutura que compõem o verbete pleno sistematizado em arquivos separados. Por meio de um programa ZS4 Video Editor, de acesso gratuito, que edita vídeos, foram feitas as edições das imagens comum acesso e que ainda está em fase de análise e aprendizado na construção no LabLibras. Separadamente e por fases distintas se o Excell, junto ao Movie Maker e ao Power Point para gerar uma página que busca se basear na estrutura de layout do glossário criado pela Universidade Federal de Santa Catarina - UFSC.

\section{Teste de validade}

Os termos analisados serão constantemente validados junto à comunidade surda e intérpretes de Libras, que atuam nas conferências. Para tanto são feitos encontros mensais junto ao grupo no LabLibras da UnB. Nestes encontros líderes surdos, da cidade de Brasília e outros estados, que participam dos eventos com o CONADE e CONAE, se comprometeram a utilizar os termos e fazerem uma avaliação sobre a aceitação do mesmo pela comunidade.

Com os intérpretes foi feito um processo diferenciado. A equipe reapresentou os textos originalmente escolhidos e antes de uma possível tradução, ofereceu por meio de um DVD contendo os termos na forma de verbete, ou seja, um glossário do texto. Foi pedido então que os intérpretes lessem os textos e caso tivessem dúvidas utilizassem o DVD. 


\section{Discussão em processo}

Todo o processo conceitual, de construção do verbete em Libras é muito recente, parte das pesquisas ainda está em consolidação. O trabalho, aqui apresentado, vem analisar a constituição de um glossário bilíngue para intérpretes de Libras que atuam em conferências nacionais. A partir de questionamentos que surgiram dentro do Laboratório de Linguística da Língua de Sinais - LabLibras surge a proposta de uma estrutura de verbete nas duas línguas. $\mathrm{O}$ intuito é deixar claro o conceito linguístico e o contexto no qual cada termo ocorre. Após discussões acadêmicas, analises do grupo em dicionários e glossários da língua portuguesa e leituras de textos voltados para a área da Terminologia, chegou-se inicialmente a um modelo de verbete pleno na língua portuguesa conforme o apresentado abaixo.

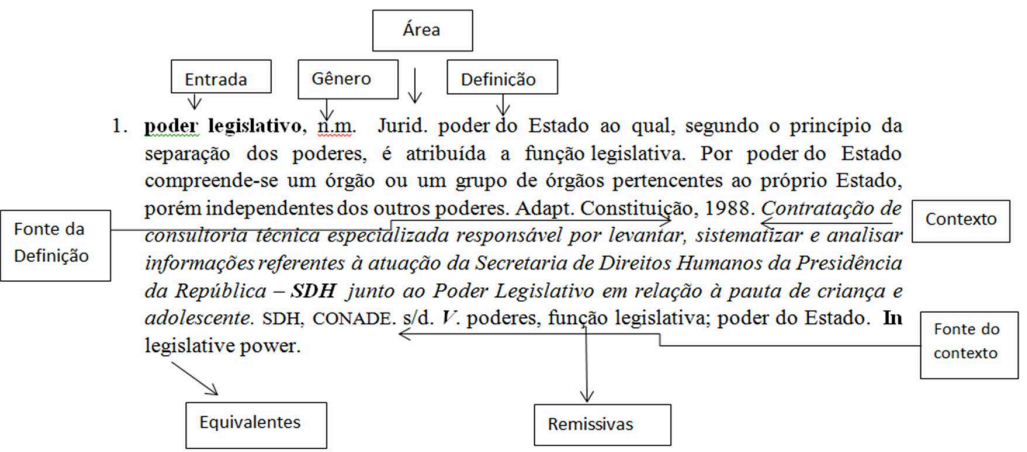

Com o verbete, na língua portuguesa, definido, passou-se a buscar o verbete pleno em Libras. Durante esta pesquisa algumas outras formas de verbete em Libras foram encontradas. Seguem alguns exemplos abaixo. 


\section{Verbete I}

Figura 3 - Glossário Bilíngue - Amamentação em LIBRAS

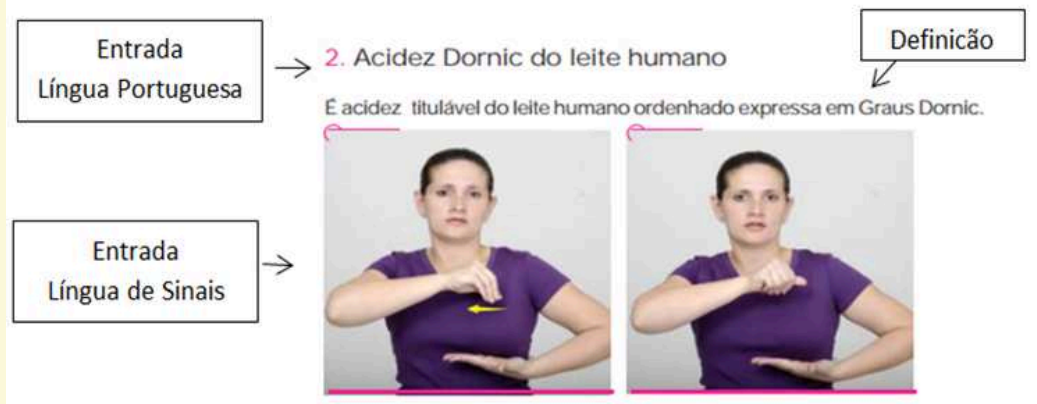

Fonte: http://www.saude.ms.gov.br

\section{Verbete II}

Figura 4 - Terminologia da Política Brasileira - LIBRAS / Língua Portuguesa

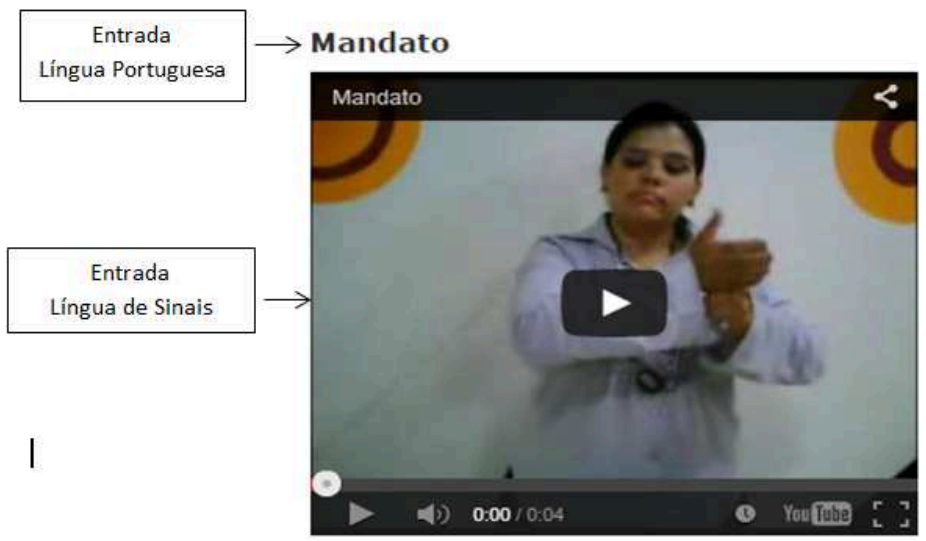

Fonte: $\underline{\text { http: }: / \text { politicaemlibras.blogspot.com.br }}$ 
Verbete III

Figura 5 - Glossário de sinais-termos dos Orixás da nação Ketu

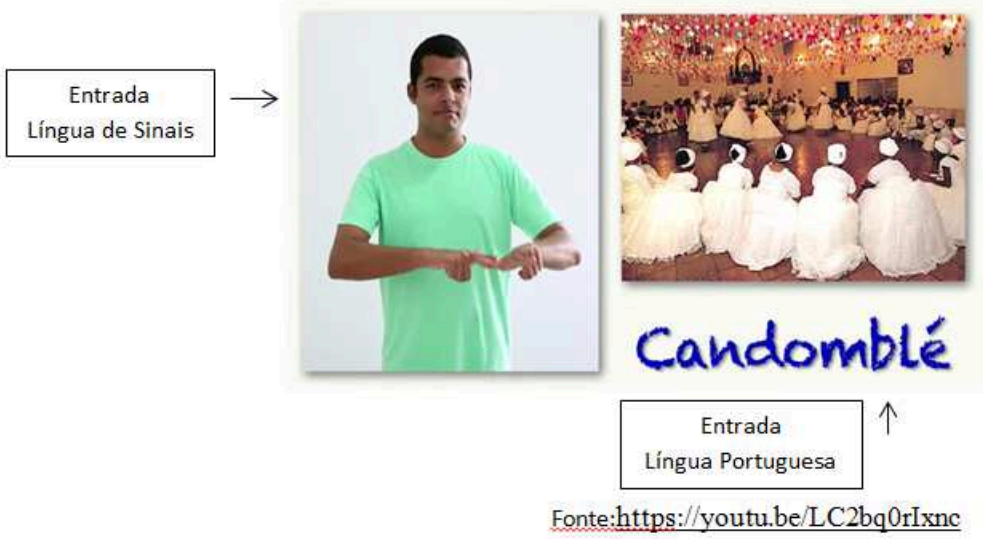

Os verbetes acima fazem parte de glossários de diversas áreas, em Libras. Ao analisar as imagens é possível perceber a diferença de estruturas apresentadas. As entradas não possuem um padrão de construção e sem elementos conceituais. Os glossários deixam de apresentar a estrutura canônica do verbete que segundo Faulstich (2014), é a principal parte define e onde estão os elementos de formação do conceito do signo linguístico apresentado na entrada.

Pensando em um verbete pleno, a equipe de pesquisa do LabLibras propõem, como resultado inicial, uma estrutura de verbete composta de:

- entrada - em ambas as línguas ( Libras e língua portuguesa);

- definição - em ambas as línguas (Libras e língua portuguesa);

- contexto - em ambas as línguas (Libras e língua portuguesa) e se necessário extensão do contexto. 
Durante as discussões de produção, foi apontado com ponto principal que as duas línguas fossem apresentadas. Pois para ser entendido como glossário bilíngue se faz necessário às duas línguas. Abaixo segue a proposta de glossário bilíngue apresentada pela equipe do Laboratório de Linguística de Língua Brasileira de Sinais - LabLibras.

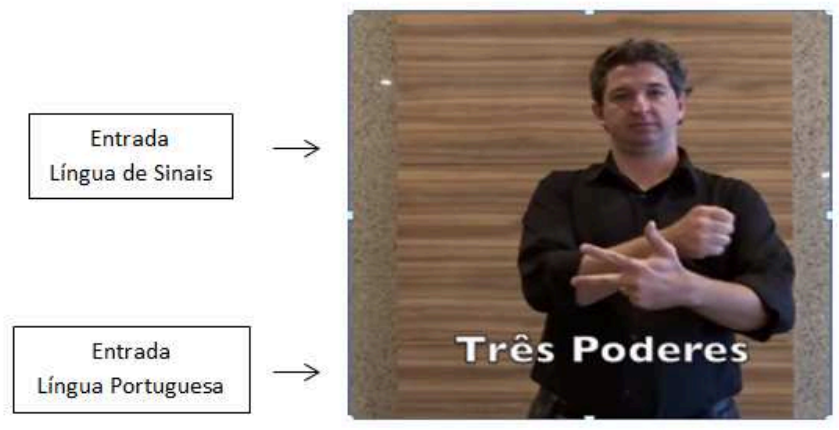

Figura 7-Definição do verbete bilíngue - termo-Três Poderes
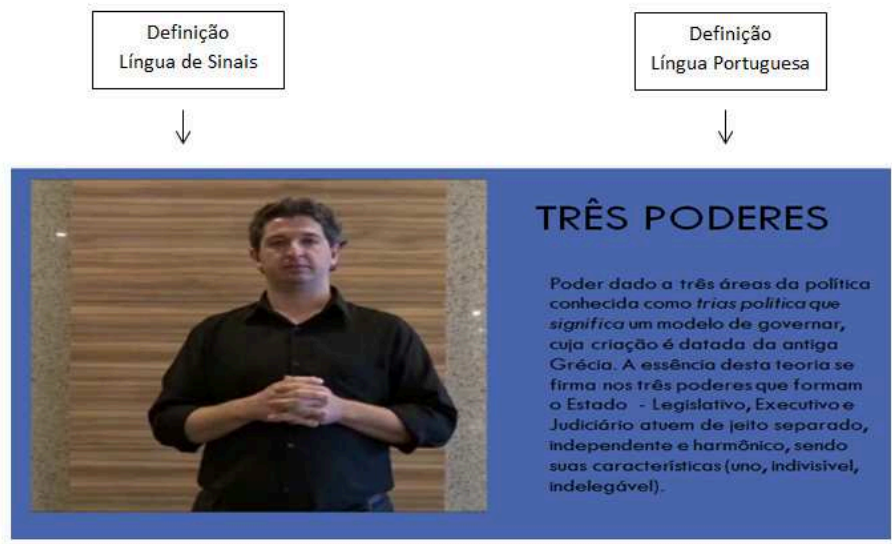
Figura 8-Contexto do verbete bilíngue - termo-Três Poderes

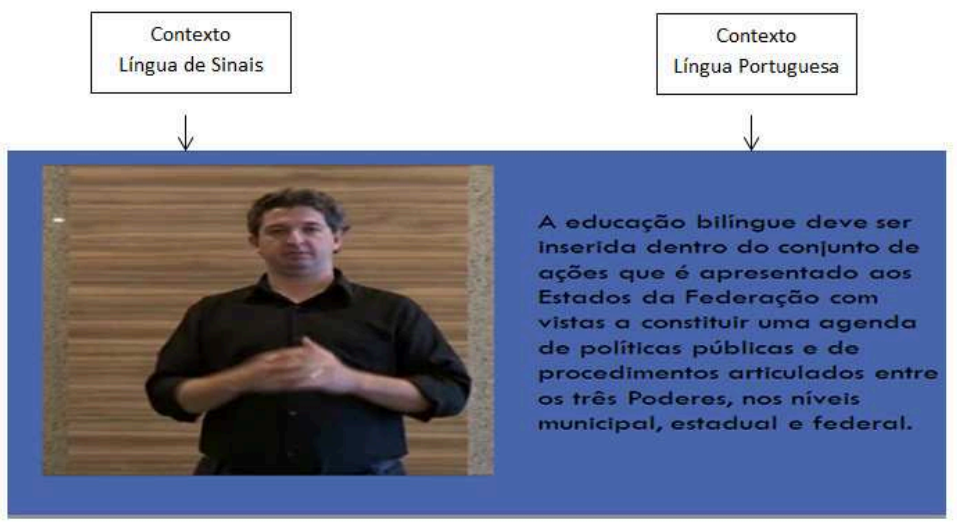

\section{Conclusão}

A constante luta pelos direitos e empoderamento, seja linguístico, identitário ou cultural da comunidade surda dentro dos meios políticos, sociais e educacionais trouxe uma revolução de novos sinais dentro do campo linguístico da Libras.

A partir do reconhecimento pela Lei 10.435/2002, surge o curso de Letras-Libras que demanda toda uma estrutura de organização e estudo dos sinais gerando aspetos de sistematização de língua até antes não vistos. Criar o glossário que atende o curso, nasce de uma ideia advinda de um material recebido para participar de um congresso pela Professora Marianne Stumpf e se torna um espaço de neologismos de língua que hoje é utilizado por todo o espaço nacional e internacional (STUMPF; OLIVEIRA; MIRANDA, 2014).

Os glossários passaram então a ter um espaço de uso para a comunidade surda e também de grande aprendizado para os intérpretes que atuavam e atuam na área. Pela necessidade, pelo conforto de acesso e claramente no intuito político de crescimento linguístico a criação de glossários aumentou de forma significativa.

Segundo Santos (2013) a produção de pesquisas desenvolvidas na área da tradução que envolve a língua de sinais ou a figura do 
tradutor e do intérprete é ainda muito pequena. Poucos são os materiais disponíveis que possam auxiliar no processo de formação destes profissionais.

No Brasil, a produção de pesquisas que contemplem o estado da arte sobre TISL nos Estudos da Tradução é carente e parece insuficiente para determinar ações governamentais a favor da formação de profissionais da tradução e interpretação. (SANTOS, 2013, p.184).

$\mathrm{O}$ verbete pleno foi utilizado com um grupo de dois interpretes, em uma interpretação feita para a Secretaria de Direitos Humanos - SDH. Antes de iniciar a conferência, que foi vinculada via internet nacionalmente, os interpretes foram convidados a assistir um DVD, contendo termos centrais relacionados ao discurso que seria feito. O vídeo foi visto pelos interpretes duas vezes. Posterior ao vídeo as interpretes sentiram necessidade de sinalizar o contexto apresentado. Ao final do trabalho de interpretação foi possível constatar que o instrumento auxiliou os interpretes que participaram do evento e também outros profissionais da área de Libras observaram e elogiaram a padronização nos termos utilizados. A pesquisa percebeu que o impacto do glossário junto aos interpretes foi satisfatória e de importante valia para todo o processo.

\section{Referências}

CASTRO JÚNIOR, Gláucio de, Variação Linguística em Língua de Sinais Brasileira - Foco no Léxico. Dissertação apresentada ao Programa de Pós-graduação do Departamento de Línguística, Português e Línguas Clássicas - LIP - Universidade de Brasilia - 2011 
CASTRO JÚNIOR, Gláucio de - Projeto Varlibras. Tese apresentada ao Programa de Pós-graduação do Departamento de Línguística, Português e Línguas Clássicas - LIP. Universidade de Brasília - UnB- 2014.

CRUZ, C. L. S. . O constructo de Faulstich para a variação das Unidades Terminológicas Complexas. Confluência (Rio de Janeiro), v. 41/42, p. 96-126, 2012.

SCHERE, Amanda Eloina e KADER, Carla Callegaro Corrêa - Os aspectos linguísticos da tradução à luz dos pressupostos teóricos de Roman Jakobson versus a vertente da tradução da linguística de corpus. Entretextos, Londrina, v.12, n.1, p.132-148, jan./jun. 2012.

GUERINI, A ; PEREIRA, M. C. P.. Introdução aos Estudos da Tradução. 2008. - (Desenvolvimento de material didático ou instrucional - Disciplina). - Curso de Letras Libras - Universidade Federal de Santa Catarina - UFSC.

ECO, Umberto. Quase a mesma coisa. Experiências de tradução. Rio de Janeiro/ São Paulo: Record, 2007. Tradução de Eliana Aguiar.

FAULSTICH, Enilde. Base metodológica para pesquisa em socioterminologia: termo e variação. Brasília: Universidade de Brasília/LIV, 1995a.

. Socioterminologia, mais que um método de pesquisa, uma disciplina.

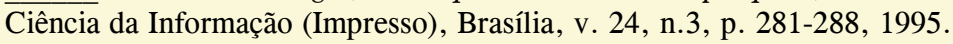

FAULSTICH, Enilde. A socioterminologia na comunicação científica e técnica. Cienc. Cult., São Paulo, v. 58, n. 2, June 2006 . Available from $<$ http://cienciaecultura.bvs.br/scielo.php?script $=$ sci_arttext\&pid $=$ S0009$-67252006000200012 \& \operatorname{lng}=$ en\&nrm $=$ iso $>$. access on 03 Sept. 2015

. Para gostar de ler um dicionário. In: RAMOS, C. de M. de A; BEZERRA, J. de R. M.; ROCHA, M. de F. S.. (Org.). Pelos caminhos da Dialetologia e da Sociolinguística: entrelaçando saberes e vidas. 1ed.São Luís: UFMA, 2010, v. 1 , p. $166-185$.

. Metodologia para Elaboração de Dicionários, Glossários e Léxicos, com Modelo de Fichas de Terminologia e de Verbete. Departamento de Linguística, Português e Línguas Clássicas - LIP- IL - UNB.Centro de Estudos Lexicais e Ter- 
minológicos - Centro Lexterm, Brasília, 2014 - Trabalho entregue em laboratórios de Lexicologia e Terminologia turma Pós-Graduação.

Glossário de sinais-termos dos Orixás da nação Ketu - Publicado em 27 de maio de 2015 no youtube https://youtu.be/LC2bq0rIxnc.

HAENSCH, G. et al. La lexicografia. De la lingüistica teórica a la lexicografia práctica. Madrid: Gredos, 1982. p. 95-153.

; FINATTO, Maria J.B. Introdução a Terminologia teoria \& prática - São Paulo: Contexto, 2004.

KRIEGER e MACIELl, Anna Maria Becker. Temas de Terminologia. Porto Alegra/ São Paulo: Ed. Universidade/ UFRGS/ Humanitas/USP, 2011.

.Temas de Terminologia. Porto Alegra/ São Paulo: Ed. Universidade/ UFRGS/ Humanitas/USP, 2011.

MARINI, SÁTIA. Da tradução terminológica em glossário temático na área de saúde suplementar. Dissertação - Universidade de Brasília, Instituto de Letras, Departamento e Línguas Estrangeiras e Tradução - 2013.

OLIVEIRA, Janine S. e STUMPF, Marianne R. Desenvolvimento de glossário de Sinais Acadêmicos em ambiente virtual de aprendizagem do curso Letras- Libras. Informática na Educação: teoria e prática- Porto Alegre, v. 16, n.2, jul/dez. 2013.

OLIVEIRA, Janine Soares de. Glossário Letras - Libras como ferramenta para Formação/ Consulta de Tradutores - II Congresso Nacional de Pesquisa em Tradução e Interpretação de Língua de Sinais Brasileira, UFSC, 2010.

PAVEL, Silvia e NOLET, Diane, Manual de Terminologia - Adaptação para língua portuguesa por Enilde Faulstich, 2002.

Projeto Sinal Aberto - Apresentado no site (https://projetosinalaberto.wordpress. $\mathrm{com} /$ ) 
SANTOS, Silvana Aguiar dos. Tradução/Interpretação de língua de sinais no Brasil: Uma análise das teses e dissertações de 1990 a 2010. Tese - Universidade Federal de Santa Catarina, Centro de Comunicação e Expressão. Programa de Pós-Graduação em Estudos da Tradução. 2013.

SÁTIA, Clarissa Prado. Glossário de leituras de "Die Aufgabe des Ubersetzers"de Walter Benjamin: Uma contribuição para a História Conteporânea da Tradução. Dissertação . Brasília-DF: Universidade de Brasília: UnB / Departamento de Línguas Estrangeiras e Tradução, 2015.

WELKER, Herbert Andreas. Dicionários - uma pequena introdução à lexicografia. 2.ed. revista e ampliada- Brasília: Thesaurus, 2004.

SEGALA. Rimar Ramalho. Tradução Intermodal e Intersemiótica/ Interlingual: Português brasileiro escrito para Língua Brasileira de Sinais. - Dissertação de Mestrado apresentada ao Curso de Pós-Graduação em Estudos da Tradução como requisito para o processo de defesa 2010. - UFSC - 2010

SESMS/ SEEMS - Secretaria de Estado de Saúde Mato Grosso do Sul e Secretaria de Estado de Educação de Mato Grosso do Sul. Glossário Bilíngue Amamentação em LIBRAS em http://www.saude.ms.gov.br/controle/ShowFile. php?id=115652)

Terminologia da Política Brasileira - LIBRAS / Língua Portuguesa - Apresentado no site (http://politicaemlibras.blogspot.com.br/) acessado em 01 de junho de 2015.

TUXI, P. A atuação do intérprete educacional no ensino fundamental. 2009. Dissertação (Mestrado em Educação) - Faculdade de Educação, Universidade de Brasília, Brasília, 2009.

Recebido em: 15/07/2015 Aceito em: 30/09/2015 